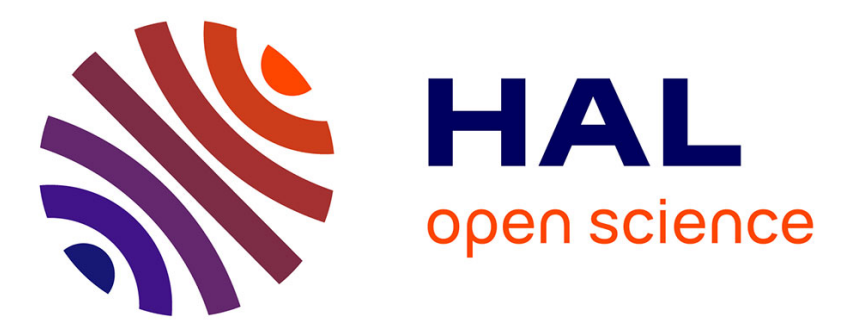

\title{
Evolutionary techniques for the synthesis of 2-D FIR filters
}

\author{
Kamal Boudjelaba, Djamel Chikouche, Frédéric Ros
}

\section{To cite this version:}

Kamal Boudjelaba, Djamel Chikouche, Frédéric Ros. Evolutionary techniques for the synthesis of 2-D FIR filters. IEEE Statistical Signal Processing Workshop (SSP), Jun 2011, Nice, France. pp.601 604, 10.1109/SSP.2011.5967771. hal-01076872

\section{HAL Id: hal-01076872 https://hal.science/hal-01076872}

Submitted on 23 Oct 2014

HAL is a multi-disciplinary open access archive for the deposit and dissemination of scientific research documents, whether they are published or not. The documents may come from teaching and research institutions in France or abroad, or from public or private research centers.
L'archive ouverte pluridisciplinaire HAL, est destinée au dépôt et à la diffusion de documents scientifiques de niveau recherche, publiés ou non, émanant des établissements d'enseignement et de recherche français ou étrangers, des laboratoires publics ou privés.

$$
\text { Copyright }
$$




\title{
EVOLUTIONARY TECHNIQUES FOR THE SYNTHESIS OF 2-D FIR FILTERS
}

\author{
Kamal Boudjelaba ${ }^{l}$, Djamel Chikouche ${ }^{2}$, Frédéric Ros ${ }^{l}$ \\ e-mail: kamal.boudjelaba@univ-orleans.fr,dj_chikou@yahoo.fr, frederic.ros@univ-orleans.fr \\ 1. Prisme Laboratory, IRAuS Pole, Axis Image and vision, Polytech'Orléans, 12 rue de Blois, Orléans, France
}

2. Electronics Department, University of M'sila, Rue Ichebilia, M'sila, Algeria

\begin{abstract}
This paper presents an objective and comparative study of evolutionary algorithms applied for designing two dimensional (2-D) FIR filters. The design of 2-D FIR filters can be formulated as a non-linear optimization problem. We explore several stochastic methodologies capable of handling large spaces. We finally propose a new genetic algorithm where some concepts are introduced to optimize the trade-off between diversity and elitism in the genetic population. All these characteristics make this study a general and effective one for revealing the performance of evolutionary algorithms.
\end{abstract}

Keywords - Genetic algorithm, tabu search, simulated annealing, hill-climbing, 2-D FIR filter.

\section{INTRODUCTION}

The digital filter is a basic building block for digital signal-processing systems and is widely used for image processing. Compared with infinite impulse response (IIR) filters, finite impulse response (FIR) digital filters are preferred in most of the communication systems due to its properties, such as guaranteed stability, linear-phase and low coefficient sensitivity [1]. A major drawback of the FIR filter is the large number of arithmetic operations involved in its implementation, which limits its speed and requires high power [1]. Several design methods for FIR filters have been investigated in the past. In these methods [2], the filters are designed by McClellan transformation, and therefore produce only suboptimal solutions. Recently, several joint optimizations [3] have been developed. The reference [3] deals with the minimax design problem of two-dimensional (2-D) linear-phase FIR digital filters with continuous and powers-of-two (POT) coefficients. First, the minimax continuous-coefficient design problem is expressed as a linear programming problem with inequality constraints. A number of well succeeded and firmly established methods of 2D digital FIR filter design and its complex associations have been proposed (e.g., [3, 4]). Recently, algorithms that utilize artificial intelligence techniques, i.e. evolutionary algorithm (EA), genetic algorithm (GA), simulated annealing (SA) and tabu search (TS), have received increasing concern in the field of global numerical optimization. In the last decades, these algorithms have been successfully applied in a wide variety of areas. However, they cannot be always effective for any optimization problems. To solve a complex optimization problem, the most effective way is to design a tailor-made algorithm that suits its needs. Alternative approaches, such as neural networks, genetic algorithms, and other tools related to computational intelligence [4, 5], have been devoted to the synthesis of design methods capable of satisfying constraints which would be unattainable, if treated with the aforementioned conventional techniques. In some cases, such initiatives were successful and showed better performance indices than the conventional approaches. However, there are a few weak points associated to these new methods, as increased computational cost and nonexistence of theoretical proof of convergence to global optimum in sufficiently general conditions. Consequently, there is a need to search for more pervasive methods, capable of overcoming such weaknesses. In this paper, 
evolutionary approaches for designing 2-D FIR filters are presented on the basis of the most popular evolutionary approaches, standard genetic algorithms (SGA), tabu search (TS) [6,7,8], simulated annealing (SA) $[9,10,11]$ and hill climbing method (HC) $[12,13,14]$. The aim is to assess the potential of these methods in their original versions for the synthesis of 2-D FIR filters. Specifically for the GA, we propose a more efficient version that accelerates the evolutionary process. The paper is divided into six sections. In section 2, 2-D FIR filters design procedure is presented. In Section 3, we review the main principles of four evolutionary approaches in their native versions. Section 4 is devoted to the presentation of a dedicated GA for the design of 2-D FIR filters. Design examples are included in Section 5. At last, conclusions are given in Section 6.

\section{DESIGN PROCEDURE OF 2-D FIR FILTERS}

The frequency response $[4,15]$ of a 2-D FIR digital filter with its impulse response $h\left(n_{1}, n_{2}\right)$ is given by:

$H\left(\omega_{1}, \omega_{2}\right)=\sum_{n_{1}=0}^{N_{1}-1} \sum_{n_{2}=0}^{N_{2}-1} h\left(n_{1}, n_{2}\right) \cdot e^{-j \cdot\left(n_{1} \omega_{1}+n_{2} \omega_{2}\right)}=M\left(\omega_{1}, \omega_{2}\right) \cdot e^{j \cdot \theta\left(\omega_{1}, \omega_{2}\right)}$

$M\left(\omega_{1}, \omega_{2}\right)=\left|H\left(\omega_{1}, \omega_{2}\right)\right|, \theta\left(\omega_{1}, \omega_{2}\right)=\arg \left(H\left(\omega_{1}, \omega_{2}\right)\right)$

Due to its symmetrical impulse response, the frequency response is given by:

$F\left(\omega_{1}, \omega_{2}\right)=\sum_{k_{1}=0}^{P_{1}} \sum_{k_{2}=0}^{P_{2}} a\left(k_{1}, k_{2}\right) * \cos \left(k_{1} \omega_{1}\right) * \cos \left(k_{2} \omega_{2}\right)$

$P_{1}=\frac{\left(N_{1}-1\right)}{2}$ and $P_{2}=\frac{\left(N_{2}-1\right)}{2}$

The sum-squared error over these frequency points is:

$E_{i}=\sum_{j=1}^{m_{1}} \sum_{k=1}^{m_{2}}\left[D\left(\omega_{1 j}, \omega_{2 k}\right)-C_{1}\left(\omega_{1 j}\right) * A_{i} * C_{2}\left(\omega_{2 k}\right)^{T}\right]^{2}$

Where $D$ is the desired magnitude response.

$$
\begin{aligned}
& C_{1}\left(\omega_{1 j}\right)=\left[\begin{array}{cccc}
1 & \cos \left(\omega_{11}\right) & \cdots & \cos \left(P_{1} \cdot \omega_{11}\right) \\
1 & \cos \left(\omega_{12}\right) & \cdots & \cos \left(P_{1} \cdot \omega_{12}\right) \\
\vdots & \vdots & \vdots & \vdots \\
1 & \cos \left(\omega_{1 m_{1}}\right) & \ldots & \cos \left(P_{1} \cdot \omega_{1 m_{1}}\right)
\end{array}\right] \\
& C_{2}\left(\omega_{2 k}\right)=\left[\begin{array}{cccc}
1 & \cos \left(\omega_{21}\right) & \cdots & \cos \left(P_{2} \cdot \omega_{21}\right) \\
1 & \cos \left(\omega_{22}\right) & \cdots & \cos \left(P_{2} \cdot \omega_{22}\right) \\
\vdots & \vdots & \vdots & \vdots \\
1 & \cos \left(\omega_{2 m_{2}}\right) & \ldots & \cos \left(P_{2} \cdot \omega_{2 m_{2}}\right)
\end{array}\right] \\
& A_{i}=\left[\begin{array}{cccc}
a_{00} & a_{01} & \cdots & a_{0 p_{2}} \\
a_{10} & a_{11} & \cdots & a_{1 p_{2}} \\
\vdots & \vdots & \vdots & \vdots \\
a_{p_{1} 0} & a_{p_{1} 1} & \cdots & a_{p_{1} p_{2}}
\end{array}\right] \\
& a_{k_{1} k_{2}} \text { is }\left(k_{1}, k_{2}\right) \text { th filter coefficient. }
\end{aligned}
$$




\section{FOUR POPULAR EVOLUTIONARY ALGORITHMS}

\subsection{Tabu search:}

Tabu search (TS) is a mathematical optimization method, belonging to the class of local search techniques [6]. The original idea of Tabu is based on the use of memory structures: once a potential solution has been determined, it is marked as "taboo" so that the algorithm does not visit that possibility repeatedly. To explore regions of the search space that would be left unexplored by the local search procedure, tabu search modifies the neighbourhood structure of each solution as the search progresses.

\subsection{Simulated annealing:}

In Simulated Annealing (SA), a system is initialized at a temperature $T$ with some configuration whose energy is evaluated to be $E$ [10]. A new configuration is constructed by applying a random change, and the change in energy $d E$ is computed. The new configuration is unconditionally accepted if it lowers the energy of the system. If the energy of the system is increased by the change, the new configuration is accepted with some random probability.

\subsection{Multi Hill-climbing:}

Hill-climbing (HC) gets its name from the fact that it assumes that the function space is "hill-shaped" [12]. Multiple solutions of the problems are coded and considered in parallel. A given set of coordinates on that landscape represents one particular solution. The algorithm starts at multiple points on the landscape and via mutations moves inexorably uphill.

\subsection{Genetic algorithm (GA):}

GA [16-18] was proposed by Holland as an algorithm for probabilistic search, learning, and optimization, and is based in part on the mechanism of biological evolution and Darwin's theory of evolution. GA repeatedly propagates generations for a large population of chromosomes by applying three operators, which consist of selection, crossover and mutation.

\section{A GA FOR FILTER DESIGN}

The main features of a standard GA are modified and integrated to yield an efficient scheme (Fig. 1). The use of nonuniform mutation and an adaptive mutation rate is to help GA escape from local optima and prevent premature convergence. A dynamic mutation rate is used to provide diversity to the population. The generation of initial population in a pseudo-randomly concept is introduced to increase convergence speed by reducing search space according to the properties of filter coefficients. This algorithm performs the direction-based crossover operator; in this case problem-specific knowledge is introduced into genetic operation in order to produce improved offspring. Furthermore, in order to perform a more precise evaluation of fitness value of chromosomes, another parameter has been used in the weighting function for evaluating fitness of chromosomes more precisely. Another important factor in our GA is the selection on enlarged sampling space. 


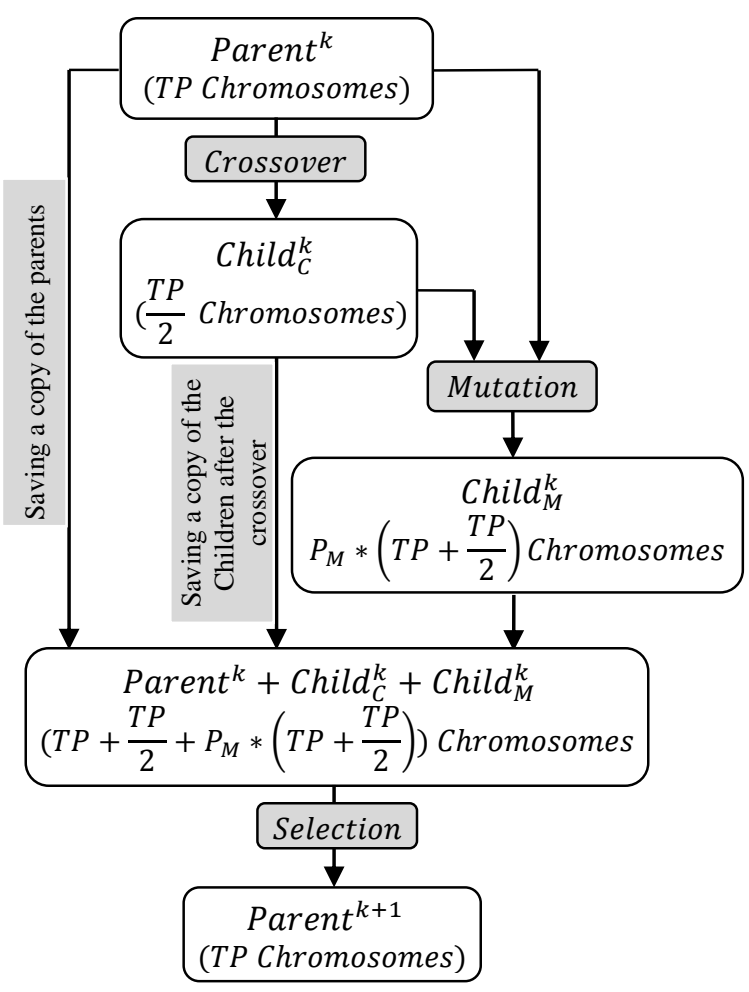

Fig. 1. Flowchart of the GA

$T P$, Child ${ }_{C}^{k}$ and $C h i l d_{M}^{k}$ are respectively the population size, and children generated by the crossover and mutation.

\subsection{Chromosome encoding and initial population}

Classical random approaches for chromosome initialization are not optimal: chromosomes have a poor total flow time and thus pass unfavorable traits to their offspring. Reeves [19] presented a population initialization method that leaded the success of the GA. In this algorithm, a new string encoding for chromosomes is used which employs the advantage of real encoding. The chromosomes are generated as follows:

$P O P_{0}=\frac{\operatorname{randn}\left(N_{1}, N_{2}\right)}{a}$

Where $N_{1} * N_{2}$ is the filter size and $a$ an integer.

\subsection{Reproduction}

In the reproduction phase, a new population is created from the current generation. The selection operation determines which parents participate in the production of offsprings in the next generation, in function of their individual fitness values. The selection probability is equal to:

$$
P_{i}=\frac{F_{i}}{\sum_{j=1}^{T P} F_{j}}
$$

Where $F_{j}$ is the fitness value of the $j^{\text {th }}$ member. 


\subsection{Selection and evaluation}

Strings are selected as parents to reproduce offspring according to their fitness values. In this research, we adopt a ranking selection scheme which prevents any domination of extra-ordinary chromosomes and wanderings among nearequals. According to the fitness values, a new generation is formed by selecting the best chromosomes from the parents and offspring, and rejecting others so as to keep the population size constant. The error criterion is:

$E_{i}=\sum_{j=1}^{m_{1}} \sum_{k=1}^{m_{2}} W\left(\omega_{1 j}, \omega_{2 k}\right) *\left[D\left(\omega_{1 j}, \omega_{2 k}\right)-C_{1}\left(\omega_{1 j}\right) * A_{i} * C_{2}\left(\omega_{2 k}\right)^{T}\right]^{2}$

$W$ : Weighting function.

Consequently, the fitness function is given by:

$F_{i}=1 / E_{i}$

\subsection{Crossover}

Direction-based crossover uses the values of objective function in determining the direction of genetic search. The operator generates a single offspring $p o p C_{i j}^{k}$ from two parents $p o p_{i}^{k}$ and $p o p_{j}^{k}$ according to the following rule:

$p o p C_{i j}^{k}=\left(\right.$ pop $\left._{i}^{k}-p o p_{j}^{k}\right) * r+p_{0} p_{i}^{k}$

Where $r$ is a random number between 0 and 1 and $k$ the index generation. It also assumes that

$f i t\left(p o p_{i}^{k}\right) \geq f i t\left(p o p_{j}^{k}\right)$

The crossover probability is $P_{C}=100 \%$.

\subsection{Mutation}

The mutation operator applies to randomly chosen individuals. The number of individuals to be varied is determined by the mutation probability $P_{M}$. The non-uniform mutation method has been adopted; the unitary operator applicable to parameter genes changes the genes value in a chromosome with each generation

$\operatorname{pop}_{i}^{k}=\frac{p o p_{i}^{k}}{2}+\frac{r}{30}$

$r$ : random number.

Probabilities of mutation are adaptively adjusted as described in eq $14[1,3]$

$P_{M}=\left\{\begin{array}{cl}\frac{k_{1} *\left(f_{\max }-f\right)}{\left(f_{\text {max }}-f_{\text {avg }}\right)} & f \geq f_{\text {avg }} \\ k_{2} & f<f_{\text {avg }}\end{array}\right.$

Where $f_{\max }$ and $f_{\text {avg }}$ are the maximum and average fitness value in the current population, respectively, and $f$ is the fitness value of the mutated chromosome. $k_{1}$ and $k_{2}$ are, respectively, the lower bound and upper bound of the mutation rate. Another notable aspect of the proposed method is its adaptive behavior. Differently from the majority of existing approaches, the weighting function is built according to the configuration presented by the specific filter during the 
initial stage of the optimization process. The practice consists in pre-establishing the weighting function before starting the optimization procedure, keeping it fixed until its end and, in case of unsatisfactory results, tuning the prescribed weighting function until reaching the desired performance.

\section{EXPERIMENTAL RESULTS AND DISCUSSION}

\subsection{Design of symmetric low-pass 2-D FIR digital filters}

Here, a $7 * 7$ symmetric low-pass 2-D FIR digital filter is designed.

This example deals with the design of a filter with the desired magnitude response:

$$
D\left(\omega_{1}, \omega_{2}\right)= \begin{cases}1 & \left|\omega_{1,2}\right|<0.5 \\ 0 & \left|\omega_{1,2}\right| \geq 0.5\end{cases}
$$

That is to say, we want to minimize the error function defined as:

$E=\sum_{j=1}^{m_{1}} \sum_{k=1}^{m_{2}} W\left(\omega_{1 j}, \omega_{2 k}\right) *\left[D\left(\omega_{1 j}, \omega_{2 k}\right)-C_{1}\left(\omega_{1 j}\right) * A * C_{2}\left(\omega_{2 k}\right)^{T}\right]^{2}$

for our GA, and

$E=\sum_{j=1}^{m_{1}} \sum_{k=1}^{m_{2}}\left[D\left(\omega_{1 j}, \omega_{2 k}\right)-C_{1}\left(\omega_{1 j}\right) * A * C_{2}\left(\omega_{2 k}\right)^{T}\right]^{2}$

for other approaches.

\subsection{Performance analysis}

The following examples show the results of the application of classical and evolutionary approaches for the design of 2D Filter. Results of the proposed design, in terms of CPU design time, width of transition band, average deviation and maximum deviation in frequency response from the desired response, are depicted in the columns of Table 1. Fig. 2 shows the frequency response obtained for a low pass filter of $7 * 7$ dimensions. Concerning the error attribute, the proposed GA is significantly lower than that obtained when other techniques are used. We can even note a factor 10 with the standard approaches. The peak errors of our GA approach and standard GA and SA are respectively 0.0851 and 0.1086 and 0.1320 . They can be considered similar to each other for this attribute and significantly better than that of the HC method, TS, frequency sampling and windowing. The filters constructed using our GA and the HC and frequency sampling method have sharper transition band responses than that produced by the GA and TS and windowing method. For the stopband region, our GA produces a better response. Our GA and standard GA have similar magnitude responses (fig. 2) for the passband and stopband regions. They have however sharper transition band responses as compared to the filter designed by the SA and windowing method. For the stopband region, the HC algorithm and frequency sampling method produce a filter whose response is a bit worse than the others. The evolutionary approaches, except for SA, are more time consuming than the classical ones. The CPU time has been qualified as "random" for the multi-hill climbing approach. This is due to a large instability that can be explained by the lack of intelligence in the approach. 


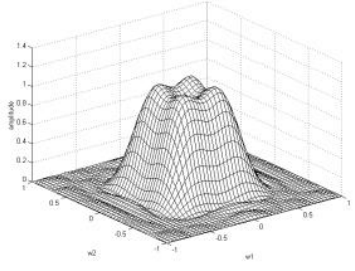

Fig.2.1. GA dedicated for designing a 2-D FIR filter

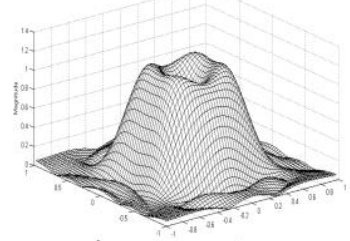

Fig.2.3. SA approach

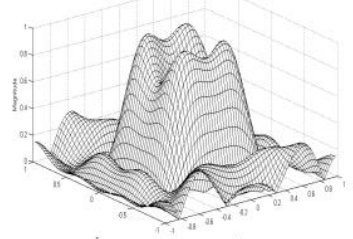

Fig.2.5. HC approach

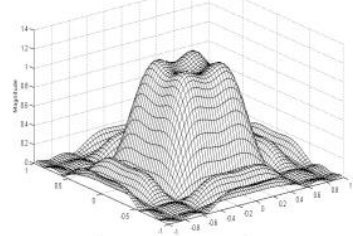

Fig.2.7. Frequency sampling

Table 1: Parameters of performance

\begin{tabular}{|l|l|l|l|l|}
\hline Parameters & $\begin{array}{l}\text { Average } \\
\text { deviation }\end{array}$ & $\begin{array}{l}\text { Peak } \\
\text { absolute } \\
\text { error }\end{array}$ & $\begin{array}{l}\text { width of } \\
\text { transition } \\
\text { band }\end{array}$ & $\begin{array}{l}\text { CPU } \\
\text { time }\end{array}$ \\
\hline $\begin{array}{l}\text { Our GA for } \\
\text { filter design }\end{array}$ & 0.0098 & 0.0851 & $\begin{array}{l}\text { Very } \\
\text { small }\end{array}$ & $625 \mathrm{~s}$ \\
\hline Standard GA & 0.0212 & 0.1086 & Small & $822 \mathrm{~s}$ \\
\hline SA & 0.0255 & 0.1320 & Middle & $108 \mathrm{~s}$ \\
\hline TS & 0.0570 & 0.2190 & Small & $660 \mathrm{~s}$ \\
\hline HC & 0.0810 & 0.3850 & Small & Random \\
\hline FT method & 0.0566 & 0.1668 & Middle & $<2 \mathrm{~s}$ \\
\hline $\begin{array}{l}\text { Frequency } \\
\text { sampling }\end{array}$ & 0.0551 & 0.2203 & $\begin{array}{l}\text { Very } \\
\text { small }\end{array}$ & $<2 \mathrm{~s}$ \\
\hline Windowing & 0.0400 & 0.4920 & Large & $<2 \mathrm{~s}$ \\
\hline
\end{tabular}

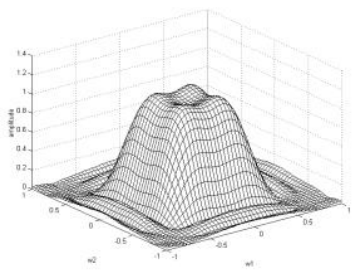

Fig.2.2. Standard GA

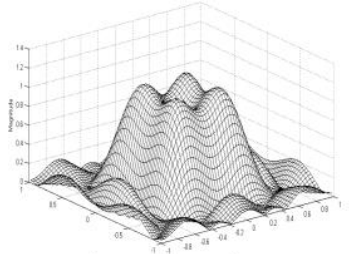

Fig.2.4. TS approach

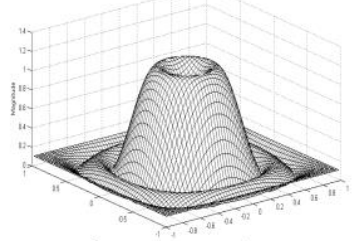

Fig.2.6. FT method

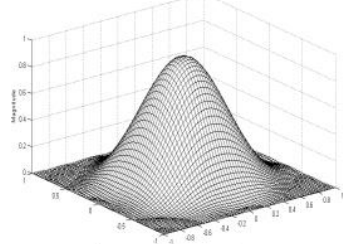

Fig.2.8. Windowing method 


\subsection{Further tests}

Our GA has been used for designing different filters under various specifications. Fig. 3 shows the frequency responses for two cases. We should note that the maximum deviation error in the designed filter response from the specified one is very small which promotes the role of evolutionary algorithms for 2-D filter design. This error is always inferior or comparable to those obtained by using other techniques. A notable aspect of the proposed method is its adaptive behavior differently from the majority of existing approaches; the probabilities of mutation are built according to the fitness values of the population. Our GA can be successfully used in digital FIR filter design. We think that all the evolutionary approaches have the potential to produce satisfactory results if the "know-how" of the domain is introduced in the algorithm, say here the use of operators tailored and specially developed for the synthesis of 2-D FIR filters. In other terms, they work well within a known context. Therefore, effort has to focus on the search of this context and not on the method itself. What we have done for GA could be done for the other evolutionary techniques hoping comparable results. Compared to other studies devoted to 2-D filter design, we can claim that our approach is more generic than approaches dealing with one or few cases of synthesis. It is filter design dedicated. It however encompasses a large domain while limiting the extensive use of genetic parameters that generally leaves end-users hopeless.

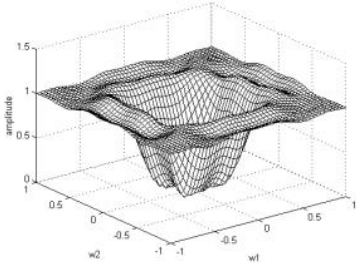

Fig.3.1. High-pass $6 * 6$

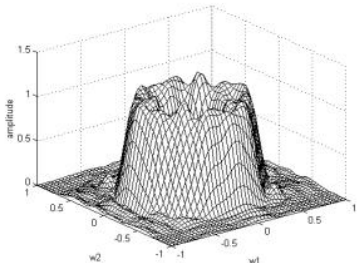

Fig.3.2. Band-pass $11 * 11$

\section{CONCLUSION}

This paper presents the optimal design methods of 2-D FIR digital filter based on evolutionary approaches. By minimizing a quadratic measure of the error in the frequency band, real-valued solutions are evolved to get the filter coefficients with the evolutionary algorithm. Several examples have been satisfactorily designed to demonstrate the efficiency of the different approaches. Our GA can produce filters with good response characteristics while greatly reducing the error criteria.

\section{REFERENCES}

[1] Ling Cen, "A hybrid genetic algorithm for the design of FIR filters with SPoT coefficients," Elsevier, Signal Processing 87, pp. 528-540, 2007.

[2] Soo-Chang Pei, Jong-Jy Shyu, "Design of two-dimensional FIR digital filters by McClellan transformation and least-squares contour mapping," Elsevier, Signal Processing 44, pp.19-26, 1995.

[3] J-H Lee, S-J Yang, D-C Tang, "Minimax design of 2-D linear-phase FIR filters with continuous and powers-oftwo coefficients," Elsevier, Signal Processing 80, pp. 1435-1444, 2000.

[4] D. Bhattacharya, A. Antoniou, "Design of 2-D FIR filters by a feedback neural network," Multidimensional Systems and Signal Processing 10, Boston, pp. 319-330, 1999.

[5] Shian-Tang Tzeng, "Design of 2-D FIR digital filters with specified magnitude and group delay responses by GA approach," Signal Processing 87, pp. 2036-2044, 2007.

[6] Glover, F., "Tabu search—part I," ORSA Journal on Computing, 1(3), pp. 190-206, 1989.

[7] Glover, F., "Tabu search—part II," ORSA Journal on Computing, 2(1), pp. 4-32, 1990.

[8] T-H Wu, J-Y Yeh, C-C Chang, "A hybrid Tabu Search Algorithm to Cell Formation Problem and its Variants," 
World Academy of Science, Engineering and Technology 53, pp. 1090-1094, 2009.

[9] S. Kirkpatrick, C.D. Gelatt, M.P. Vecchi, "Optimation by Simulated Annealing," Science 220, pp. 671-680, 1983. [10] Bohachevsky I., Jonhson M. E., Stein M.L., "Generalized simulated annealing for function optimization," Technometrics 28, pp. 209-217, 1986.

[11] D. Bertsimas and J. Tsitsiklis, "Simulated annealing," Statistical Science, vol. 8, No. 1, pp. 10-15, 1993.

[12] S.A. Dunn, "The Use Of Genetic Algorithms And Stochastic Hill-Climbing In Dynamic Finite Element Model Identification," Elsevier, Computers \& Structures Vol. 66, No. 4, pp. 489-497, 1998.

[13] S.A. Akramifar, G.Ghassem-Sani, "Fast forward planning by guide denforced hill climbing," Elsevier, Engineering Applications of Artificial Intelligence 23, pp. 1327-1339, 2010.

[14] Alan W. Johnson, Sheldon H. Jacobson, "A class of convergent generalized hill climbing algorithms," Elsevier, Applied Mathematics and Computation 125, pp. 359-373, 2002.

[15] André Quinquis, Le Traitement du Signal sous Matlab, pratique et applications, Hermès, Paris, 2000.

[16] Holland, J. H., Genetic algorithms and the optimal allocation of trials, SIAM Journal on Computing 2, 1973.

[17] K. Boudjelaba, D. Chikouche, R.E. Bekka, "Application des Algorithmes Génétiques pour La Synthèse des Filtres RIF 1-D Passe-Bas," Proceeding du $1^{\text {er }}$ Congrès International sur le Génie Electrique CIGE’04, Sétif, pp. 3640, 10-12 Octobre 2004.

[18] D. E. Goldberg, Genetic Algorithms in Search, Optimization, and Machine Learning, Addison-Wesley, Reading, MA, 1989.

[19] C. R. Reeves, "A Genetic Algorithm For Flowshop Sequencing," Computers and Operations Research 22 (1), pp. 5-13, 1995. 